\title{
La política de los presupuestos municipales: conformación de jurisdicciones fiscales en las municipalidades de campaña del Estado de Buenos Aires (1854-1860)
}

\section{The Politics of Municipal Budgets: The Conformation of Fiscal Jurisdictions in the Rural Municipalities of the Estado de Buenos Aires (1854-1860)}

\author{
Mariana Canedo \\ Universidad Nacional de Mar del Plata, Consejo Nacional de Investigaciones \\ Científicas y Técnicas, Argentina, Buenos Aires, Argentina, \\ mcanedo@mdp.edu.ar
}

\begin{abstract}
Resumen. El objetivo del trabajo es analizar la construcción de fiscalidades municipales a partir de los primeros presupuestos realizados por las municipalidades de campaña en el Estado de Buenos Aires. Argumentamos que, en el contexto de la instauración extensiva del régimen municipal en el ámbito rural, la política de los presupuestos constituyó un intento de ordenamiento fiscal y de afianzamiento de los vínculos políticos entre diferentes actores en el Estado de Buenos Aires, separado de la Confederación Argentina. Reconstruimos el proceso de elaboración de los presupuestos, analizando las variadas perspectivas del ministro de Gobierno, los representantes en las cámaras legislativas y los integrantes de las municipalidades de campaña sobre los presupuestos, la fiscalidad local y la naturaleza de las municipalidades a mediados del siglo XIX.
\end{abstract}

Palabras clave: presupuestos municipales; política; jurisdicción fiscal.

Abstract. The objective of this work is to analyze the construction of municipal fiscalities from the first budgets made by the rural municipalities in the Estado de Buenos Aires. We argued that, in the context of the extensive implementation of the municipal regime in the countryside, the policy of the budgets constituted an attempt to attain fiscal ordering and reinforcement of political relations between different actors in the Buenos Aires State, separated from the Argentine Confederation. The process of budget elaboration has been reconstructed through the analysis of the perspectives of the government ministers, the Cámara de Representantes and the members of rural municipalities.

Key words: municipal budget; politics; fiscal jurisdiction.

Am. Lat. Hist. Econ., may.-ago., 2018, pp. 146-174 | DOI: 10.18232/alhe.870 
JEL: N260; N460.

Fecha de recepción: 14 de marzo de 2017. Fecha de aceptación: 25 de agosto de 2017.

Organismo colaborador: Consejo Nacional de Investigaciones Científicas y Técnicas, Argentina.

\section{INTRODUCCIÓN}

$\mathrm{H}$ ace unos años, Marcello Carmagnani (2010, p. 357) se refirió a la política de presupuesto para poner de manifiesto la intensa vida parlamentaria en México hacia las últimas décadas del siglo XIX. Las modificaciones a las propuestas presidenciales en el Congreso le permitieron resaltar el funcionamiento de la división de poderes, considerado un rasgo liberal subyacente en todo presupuesto, a la vez que analizar las particularidades de los presupuestos decimonónicos. El propósito de este artículo es abordar esa línea de investigación que articula fiscalidad y política a partir de los presupuestos, incorporando la fase de elaboración de estos, previa al tratamiento en el poder legislativo y poner en evidencia la participación de otros actores. El caso seleccionado está constituido por los presupuestos realizados por las municipalidades de campaña en el Estado de Buenos Aires a mediados del siglo XIX.

A principios de 1852, Juan Manuel de Rosas, gobernador de Buenos Aires por más de 20 años, fue derrotado por una coalición de fuerzas de Brasil, Uruguay y las provincias de Corrientes y Entre Ríos. Sin embargo, diferentes conflictos en la coalición triunfante relacionados con el liderazgo de Justo José de Urquiza, gobernador de Entre Ríos, y el control de la aduana porteña condujeron a la separación de la provincia de Buenos Aires de la Confederación Argentina hasta 1861. La consecuente conformación del Estado de Buenos Aires con el libre ejercicio de su soberanía interior y exterior, como indicaba el primer artículo de su Constitución sancionada en 1854, no evitó la convulsión política interna ni enfrentamientos con la Confederación y grupos indígenas (Bonaudo, 2007; Jong y Ratto, 2008; Scobie, 1964). En este contexto, quienes gobernaron Buenos Aires -una alianza de liberales que había apoyado a Urquiza y antiguos rosistas- lograron el consenso suficiente para impulsar el desarrollo políticoinstitucional del Estado soberano en diferentes esferas de funcionamiento (Halperín, 1995). A mediados del siglo XIX, seguía siendo un desafío gobernar una campaña cada vez más populosa, con pobladores cansados de las levas, contribuciones económicas y enfrentamientos bélicos que no manifestaban un claro apoyo hacia el nuevo gobierno (Fradkin y Gelman, 
2015). El establecimiento del régimen municipal en la ciudad homónima y en unos 40 pueblos rurales adquirió una especial importancia.

En Buenos Aires, los pueblos -denominados "de españoles", aunque su composición era variada- se conformaron vinculados a circuitos comerciales orientados hacia Potosí, Paraguay, Chile o la propia ciudad puerto hacia mediados del siglo XVIII. Cada uno tuvo su propio proceso de constitución: fueron impulsados por ocupantes de tierras realengas, surgieron de pueblos de indios, promovidos por propietarios de tierra o por un virrey, entre otras posibilidades (Canedo, 2016). Los pueblos, cercanos y comunicados entre sí, accedieron a prerrogativas reales, aunque sin alcanzar la titulación de villa (con la excepción temprana de la villa de Luján), por lo que quedaron gobernados por los alcaldes de la Santa Hermandad, nombrados por el cabildo de Buenos Aires, y en la década de 1820 por los jueces de paz designados por el gobernador. Hacia 1810, estimamos que habría 30 pueblos con diferente estado de consolidación y cantidad de pobladores, a los que se agregarían unos catorce antes de 1860, en una jurisdicción territorial que se extendió hacia el sur y el oeste. ${ }^{1}$

El conocimiento sobre la fiscalidad y los presupuestos tanto en el Estado de Buenos Aires como en la Confederación Argentina se ha consolidado en los últimos años por Garavaglia $(2007,2015)$ y Garavaglia y Caselli (2013). Sin embargo, el conocimiento sobre la fiscalidad municipal decimonónica es todavía fragmentado, fundamentalmente en los ámbitos rurales. ${ }^{2}$ Pese a la amplia extensión del régimen municipal en el Estado de Buenos Aires, los presupuestos locales constituyen una experiencia que ha pasado inadvertida por la historiografía tanto en la práctica política como en la fiscalidad local.

El objetivo del artículo es reconstruir y analizar los procesos de conformación de los primeros presupuestos municipales como instrumentos de las políticas entabladas entre el gobierno, las cámaras y las municipalidades de campaña en el Estado de Buenos Aires. Argumentamos que la política de los presupuestos en las fases de elaboración y aprobación previas al tratamiento legislativo constituyó un intento de ordenamiento fiscal y de afianzamiento de los vínculos políticos entre diferentes actores en el Estado de Buenos Aires. Particularmente, consideramos que la construcción de jurisdicciones fiscales locales en el contexto de la formación del estado soberano, enfrentamientos bélicos y la instauración extensiva del régimen municipal, constituyó un campo dinámico de negociación producto de

\footnotetext{
${ }^{1}$ Para perspectivas de conjunto sobre los pueblos rurales en Buenos Aires en los siglos XVIII y XIX, véanse Barral y Fradkin (2005), Canedo (2016), Paula y Gutiérrez (1999).

${ }_{2}^{2}$ Son excepciones sobre la fiscalidad municipal Bonaudo y Sonzogni (1997) y Ríos (2013) para Santa Fe; Conti y Boto (1997) para Jujuy; Sanjurjo (2004) para Mendoza, y Canedo (2011a) y Garavaglia (2015) para Buenos Aires.
} 
la intervención de las municipalidades con sus propios intereses, y que no fue sólo producto de decisiones unidireccionales y homogéneas de las cámaras y el gobierno.

Las fuentes principales del trabajo son los presupuestos municipales, la legislación correspondiente, actas de sesiones de la Cámara de Representantes y notificaciones de los ministros. Hemos logrado ubicar información sobre 89 presupuestos elaborados entre 1856 y 1859 (más cinco primeras versiones realizadas en 1856), que se encuentran dispersos en el Archivo del Ministerio de Gobierno del Estado de Buenos Aires (en adelante MGEBA) en el Archivo General de la Nación (AGN). Para los tres primeros años contamos con doce, 35 y trece presentaciones, respectivamente, realizadas por las municipalidades al ministro de Gobierno. Para 1859, encontramos la planilla del ministro de Gobierno con el resumen de entradas, gastos y déficits presupuestados por 28 municipalidades, $\mathrm{y}$ un presupuesto completo de la municipalidad de Ensenada ${ }^{3}$ (véase cuadro 1). Los presupuestos no siguieron un único modelo y presentaron características propias de la primera etapa de elaboración, como iremos señalando. La información más frecuente de los presupuestos, sobre la cual los municipales, el ministro de Gobierno y las cámaras centraron la atención, fueron los déficits presupuestados desde las municipalidades.

\section{LA CUESTIÓN FISCAL EN LA LEGISLACIÓN SOBRE EL RÉGIMEN MUNICIPAL}

El régimen municipal será establecido en todo el Estado. La forma de elección de los municipales, los atributos y deberes de estos cuerpos, como lo relativo a sus rentas y arbitrios, serán fijados en la ley de la materia (Constitución del Estado de Buenos Aires, 1854, libro 32, art. 170).

La organización del régimen municipal constituyó un tema recurrente en la agenda de las políticas del Estado de Buenos Aires. Desde su propia conformación, estuvieron incluidas en la Constitución (1854) la ley de municipalidades (1854), el reglamento de municipalidades de campaña (1856) y en otras leyes y decretos más específicos que se sancionaron con relativa rapidez en una coyuntura conflictiva. ${ }^{4}$ Pese a lo heterogéneo que eran los pueblos hacia mediados del siglo XIX, en el gobierno y en la le-

${ }^{3}$ Los presupuestos se encuentran expresados en pesos de moneda corriente. Para estimarlos en peso fuerte hay que considerar los siguientes promedios de la cotización anual: año 1856 (20.41 peso fuerte), 1857 (19.81 peso fuerte), 1858 (21.39 peso fuerte), 1859 (21.39 peso fuerte).

${ }^{4}$ Entre los pocos estudios con referencias a las municipalidades de campaña se encuentran Birocco (2009), Paredes (1995), Recalde (2009) y Ternavasio (1991). 


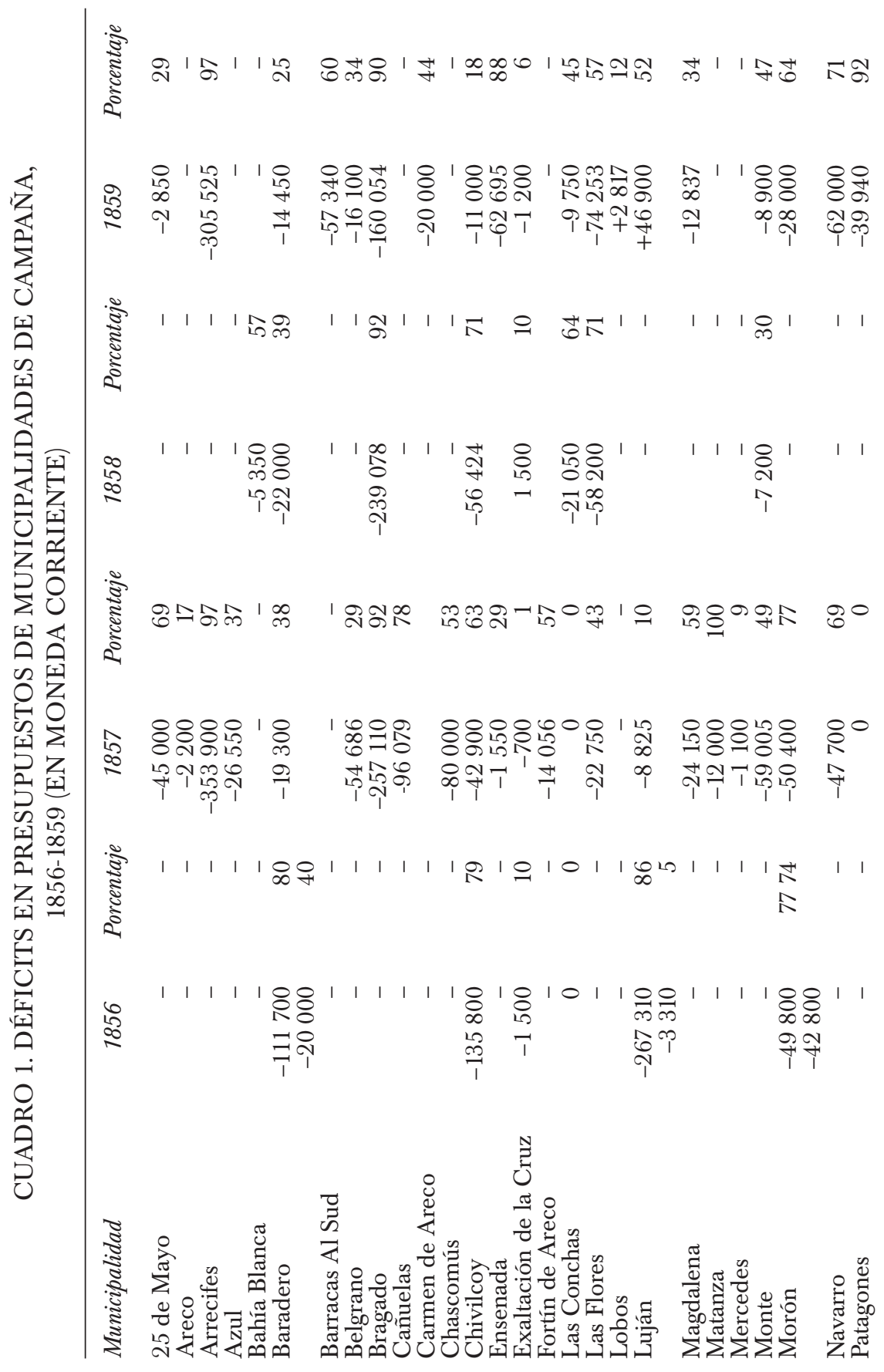




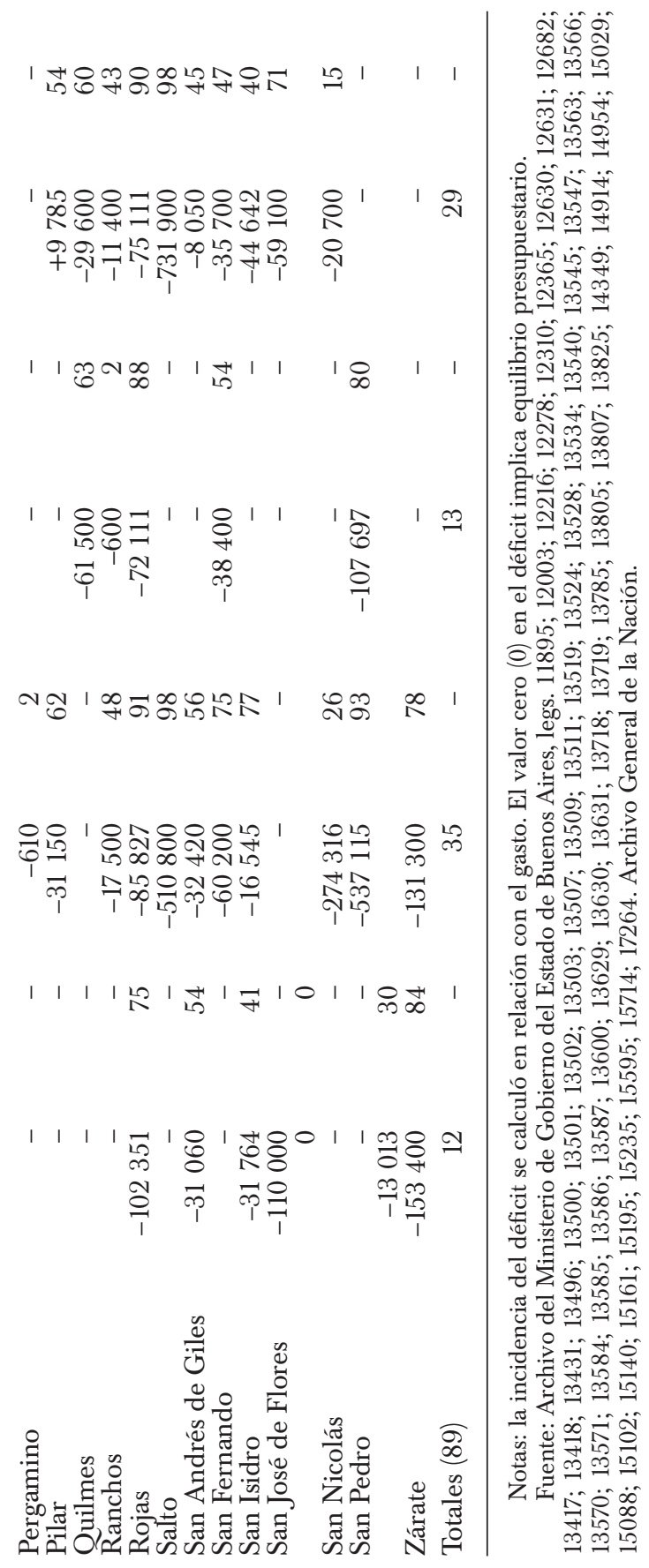


gislación se buscaron la uniformidad administrativa y la simultaneidad de instrumentación de las disposiciones. Las notificaciones de las autoridades del gobierno llegaban a todos los partidos o jurisdicciones a cargo de un juez de paz, pero las municipalidades se organizaron en aquellos en los que había un pueblo constituido (sin considerar mínimos de población ni distancia entre ellos). Así, de los 53 partidos o jurisdicciones a cargo de un juez de paz, según los nombramientos de 1860, en 41 de ellos figuraba una municipalidad de campaña (77\%).

La lectura de las leyes y reglamentos desde el aspecto fiscal permite advertir las concepciones que desde el gobierno y las cámaras se tenían del régimen municipal, particularmente de las nuevas municipalidades de campaña. La ley de municipalidades se organizó en dos secciones: para la ciudad (56 artículos) y para la campaña (20 artículos). Como sucedió en otras regiones, las municipalidades de campaña fueron consideradas las encargadas del régimen económico y administrativo de cada uno de los partidos (artículo 57)..$^{5}$ Debían "promover y consultar los intereses materiales y morales del partido, con absoluta prescindencia de los intereses políticos" y propondrían al gobierno (ministro, secretaría o departamento, según el tema) "cuantas medidas considere conducente al mejor orden, seguridad y prosperidad del Partido" (artículo 63). Sus amplias funciones incluían la administración de justicia, la policía, la instrucción pública, los establecimientos de beneficencia, el culto, la adjudicación de solares y la propuesta anual de alcaldes y tenientes del partido.

En el ámbito fiscal, la ley permitía a las municipalidades de campaña "la creación y administración de las rentas municipales, y de toda obra costeada por sus fondos" (artículo 63). Dentro de las municipalidades se estipulaba un encargado de la recaudación de las rentas municipales, quien también debía percibir los fondos que destinaba el gobierno para el servicio del partido. Sus labores incluían "la contabilidad en el orden y método que será prescripto por la Contaduría General" así como inspeccionar y correr "con los gastos de toda obra ordenada por la municipalidad" (artículo 68). En el Reglamento de las Municipalidades de Campaña, aprobado dos años después, se precisaba el funcionamiento que se esperaba de las mismas: cómo debían proceder, fechas por cumplir, a cuál instancia del gobierno dirigirse por consultas, etc. En relación con el ámbito fiscal, se especificaron las rentas municipales y el mes de presentación de los presupuestos anuales. También se incorporaron obligaciones del recaudador de rentas (artículos 7 y 12) y del secretario de cada municipalidad (siete incisos del artículo 33).

\footnotetext{
${ }^{5}$ Sobre la historicidad del carácter administrativo de los gobiernos, véase Barriera (2010), entre otros.
} 
La legislación, con sus anhelos regulatorios y homogeneizadores, no da cuenta de la complejidad que implicó la instalación de las municipalidades en Buenos Aires a mediados del siglo XIX. Si bien las funciones atribuidas a los jueces de paz en los pueblos de la campaña se habían incrementado paulatinamente, en algunos ámbitos la experiencia requirió de nuevas prácticas, definiciones y cesiones de potestades que involucraron no sólo a las propias municipalidades, sino también a los poderes ejecutivo y legislativo del nuevo Estado de Buenos Aires.

\section{ENTRE EL GOBIERNO Y LAS CÁMARAS: PERSPECTIVAS SOBRE LAS MUNICIPALIDADES}

En 1856, el propio gobierno fue quien solicitó aclaraciones para poner en práctica los primeros presupuestos municipales en un ejemplo de la complejidad del proceso. La elaboración de estos formaba parte de la conformación de las jurisdicciones fiscales municipales que eran otorgadas a la ciudad de Buenos Aires, que había dejado de disponer de ellas varias décadas atrás, con la supresión de los cabildos en 1821 y la consecuente concentración en la jurisdicción provincial. A su vez, se asignaban prerrogativas fiscales a los pueblos rurales que no las habían tenido.

En 1856, el debate en la sesión de la Asamblea General discurrió sobre tres ejes interrelacionados: quién debía aprobar los presupuestos de gastos; con qué recursos contaban las municipalidades para cubrirlos, y cuál era la naturaleza de las mismas. Específicamente, el ministro de Hacienda marcaba la urgencia de deslindar las rentas propias de las municipalidades de las rentas generales del Estado (Acta Asamblea General, 27 de junio de 1856, Estado de Buenos Aires, fs. 186-191).

La ley facultaba a las municipalidades para nombrar empleados cuyos sueldos debían ser presupuestados. ¿Se debían aceptar todos los gastos de las municipalidades? ¿Quién debía aprobar sus presupuestos? El ministro consideraba que, en caso de que fuese el gobierno, se limitaría la independencia que debía tener la municipalidad en sus atribuciones y administración, y proponía que fuesen directamente las cámaras las que lo hiciesen. A su vez, la comisión de negocios constitucionales de la cámara consideraba que mucho había que hacer respecto a las atribuciones de las municipalidades, pero, dada la coyuntura, realizaba una propuesta sin dudas restrictiva, aunque de un alto orden político y, por ejemplo, mantenía los derechos sobre saladeros y pregonería por naturaleza municipales 
como contribuciones para el gobierno. ${ }^{6}$ Para el vocero de la comisión, "la municipalidad no es una institución libre por excelencia [...] no es más que una fracción de poder administrativo, una división de ese poder, y como tal [...] subordinada al más alto poder administrativo que se conoce en el Estado, es decir, el Gobierno" (Acta Asamblea General, 27 de junio de 1856, Estado de Buenos Aires, f. 187).

Tejedor argumentaba: "Así se acostumbra también en otros países, cuando el presupuesto es de poca monta; en las monarquías, el rey que es la potestad mayor, aprueba los actos administrativos, y en las Repúblicas deben ser las cámaras. Pero nosotros estamos en el principio de esta institución, y la ley la ha considerado como una división del Ejecutivo" (f. 188).

Entre los presentes en la sesión había coincidencia sobre la escasez de impuestos asignados a las municipalidades y se esperaba en 1856 un déficit que tendría que llenarse con las rentas del Estado. El gobierno debía separar una gran parte de sus eventuales para los gastos no sólo de la municipalidad de la ciudad, sino también de la campaña (f. 189).

Para el representante Estévez Seguí, la discusión era sobre la naturaleza propia de la institución. Afirmaba que no se debía inutilizar la municipalidad "centralizando tanto sus atribuciones que venga a depender del poder administrativo, ni elevando la descentralización al extremo de que se infringe la ley de su creación" (f. 188). Finalizaba señalando la doble responsabilidad de las municipalidades ante el gobierno y las cámaras. A su vez, Rufino Elizalde especificaba:

La municipalidad en todas partes vota su propio presupuesto cuando sus gastos no exceden sus propias rentas; pero cuando necesitan hacer gastos que exceden de sus recursos, debe dar una cuenta al poder superior para que examine los gastos, $\mathrm{y}$ si los aprueba arbitre las rentas para cubrir el déficit [...] Como hoy no tiene rentas la municipalidad, estamos reglamentándola, como un ramo de la administración; tiempo vendrá que la reglamentemos como persona moral (f. 189).

La puesta en funcionamiento de la ley ponía en evidencia diferentes perspectivas entre los representantes en la cámara y aun entre los ministros sobre las características que debían tener las municipalidades, que, sin embargo, quedaban supeditadas a considerar la coyuntura del Estado de Buenos Aires. Por mayoría de votos (21 a cinco) se adicionaron artículos a la ley que autorizaban al gobierno a pagar ese año a los empleados nom-

${ }^{6}$ Ante las dudas expresadas por el gobierno, la Comisión de Negocios Constitucionales encabezada por el jurista Carlos Tejedor había conversado con los ministros de Gobierno y Hacienda sobre las atribuciones a las municipalidades: el primero habría planteado que debían ampliarse y el segundo que estas mismas atribuciones tenían que explicarse en sentido restrictivo (Acta Asamblea General, 27 de junio de 1856, Estado de Buenos Aires, fs. 188). 
brados por las municipalidades, se precisaron las rentas municipales y se confirmó el circuito que debían seguir los presupuestos.

\section{ENTRE LAS MUNICIPALIDADES Y EL GOBIERNO: LA ELABORACIÓN DE LOS PRESUPUESTOS}

¿Cómo fue, en definitiva, el proceso de elaboración y aprobación de los presupuestos de las municipalidades de campaña? A fines de abril, cada municipalidad debía presentar al ministro de Gobierno el presupuesto de recursos y gastos que "demandará el servicio público del Partido" en el siguiente año. El gobernador, a través del ministro, podía aprobarlo o no. De ser solicitado, la municipalidad efectuaría modificaciones y volvería a presentar el presupuesto. Luego, el ministro de Gobierno incluiría en el presupuesto de su área los gastos aprobados para las municipalidades, de manera agregada, y estimaría los eventuales déficits por cubrir. El presupuesto de la ciudad de Buenos Aires quedaba diferenciado del resto de las municipalidades. Las cámaras, al tratar las partidas del presupuesto anual, podían aprobar, modificar o rechazar lo presentado por el gobierno.

Para poner en funcionamiento la dinámica de los presupuestos municipales, el ministro de Gobierno fue recordando por notas su presentación. Los presidentes de las municipalidades justificaron las demoras por dificultades para reunir a los miembros de las municipalidades: "disgusto de no haberlo conseguido en las diferentes convocatorias que he hecho" manifestaba el de San Isidro en mayo de 1856, o por "estar enfermos dos de sus miembros por cuyo motivo no funcionaba", explicaba el de Arrecifes en junio de 1857. También señalaban que no se había "instalado la municipalidad de que habla el art. 7 del reglamento" (Tordillo, 1857), o la imposibilidad de formar presupuesto por estar "arrasado este departamento por los indios", indicando que no le era "posible crearse fondos sin ocasionar males con cada real [sic] que saque a este vecindario, mil veces mayores que el bien que con ellos podrá hacer" (Patagones, 1857).

Las respuestas ponen de manifiesto el impulso del gobierno y la legislación por adecuar en forma simultánea municipalidades de campaña en todo el territorio del Estado de Buenos Aires a partir de 1856, pero también que el proceso de instalación de las municipalidades tuvo diferentes ritmos. De todas maneras, en 1857 se nombraron 52 jueces de paz y se presentaron -al menos- 36 presupuestos municipales (69 por ciento).

La estructura de los presupuestos fue variada. En un extremo hubo casos como la nota con el alquiler de una casa para juzgado y otra para municipalidad (500 pesos cada uno por mes), y el sueldo de un secretario (1 000 mensuales) presupuestados como gastos de la municipalidad de La 
Matanza. En el otro extremo, ubicamos el presupuesto de la municipalidad de Cañuelas, con estimaciones de ingresos y egresos de cada municipal según las funciones asignadas. Ambos casos fueron considerados presupuestos por las autoridades en 1857.

El gobierno fue logrando cierta regulación en las fechas de recepción, como parte del ciclo presupuestario: en 1856 se presentaron a través del año (abril, julio, agosto y octubre), en 1857 entre abril y julio (con predominio en abril y mayo), y en 1858 se concentró en abril y mayo. ${ }^{7} \mathrm{Sin}$ embargo, en 1859 la mayoría se presentó en agosto, algunos en septiembre y pocos en abril y mayo, posiblemente influidos por el endurecimiento de las relaciones y los preparativos de enfrentamientos entre Buenos Aires y la Confederación (Scobie, 1964, p. 235).

\section{LAS RENTAS MUNICIPALES}

La configuración de una jurisdicción fiscal en el ámbito de las municipalidades implicaba la cesión de algunos derechos por parte de otras jurisdicciones o la creación de nuevas rentas. Como señalamos anteriormente, los pueblos rurales no contaban con potestades fiscales propias, aunque los alcaldes de la Santa Hermandad o los jueces de paz colaboraron en la recaudación de contribuciones para otras fiscalidades ${ }^{8}$ (Galarza, 2012).

El gobierno del Estado de Buenos Aires pautó la potestad fiscal de las municipalidades en las leyes y reglamentos como una transición: especificó cuáles serían sus rentas, solicitó a las municipalidades propuestas sobre rentas y contribuciones por ser discutidas en las cámaras (Ley de Municipalidades, artículo 71) y estableció la revisión de la ley de municipalidades al año de ponerse en vigencia. Pese al reconocimiento coincidente sobre lo limitado de las rentas municipales, la restricción inicial fue renovada año tras año con escasos ajustes.

Las primeras rentas municipales en la campaña, similares a las establecidas por esos años en las ciudades capitales de las provincias de la Confederación y la ciudad de Buenos Aires, fueron autorizadas por medio de su reglamento en 1856 (artículo 71). ${ }^{9}$ El cobro de las guías a la

${ }^{7}$ El presupuesto de la municipalidad de Exaltación de la Cruz se presentó en octubre de 1856, cuando no había funcionamiento de las Honorables Cámaras. El ministro de gobierno permitió ponerlo en marcha por presentar un déficit pequeño y fácil de cubrir.

${ }^{8}$ En este sentido, resulta un ejemplo la actuación del juez de paz de Mar Chiquita al elevar el presupuesto en 1857. Planteaba que intentaba suplir las funciones de la municipalidad, si las hubiere. Sin embargo, sólo consideraba como ingresos las potestades del juez de paz ( $10 \%$ de la contribución directa y el cobro de algunas multas) (MGEBA, leg. 13807).

${ }^{9}$ Los diez derechos municipales fueron: a corrales para el abasto; multas; peaje y pontazgo; la renta obtenida de solares de propiedad pública; el canon enfitéutico por cobrar por terrenos 
circulación de productos, los derechos de corrales, o de patentes, pesas y medidas -que ya se cobraban en los diferentes partidos como rentas provinciales-, fueron los impuestos más presentes en las estimaciones de las municipalidades de la campaña. ${ }^{10}$ Peaje y pontazgo y los ingresos al puerto e introducción de madera (ambos incluidos con posterioridad) tuvieron impacto en municipalidades específicas. Las entradas al puerto resultaron el mayor ingreso calculado en San Pedro (26\% del total), Zárate $(30 \%$ de 37100 pesos) y San Fernando (58\% de derecho de puertos de los 20600 pesos) (Canedo y Román, 2016).

Los derechos a multas estuvieron relacionados con el control de la propiedad del ganado, la regulación sobre las bebidas, el uso de cuchillo o los "juegos prohibidos", es decir, prácticas sociales que preocupaban a las autoridades desde el periodo colonial. Algunas municipalidades manifestaron límites en el cobro por superposición de potestades con las comisarias. En San Isidro exponían en 1857 que "por el reglamento dado a los comisarios de campaña, la mayor parte de las multas que por ley anterior pertenecían a los municipios, quedan a la fecha declaradas policiales" (MGEBA, leg. 12003). De todas maneras, dejaban constancia de que en el presupuesto presentado figuraban "todas ellas como recurso de esta municipalidad", por lo que el ministro solicitaba informe al jefe de policía.

Los eventuales o extraordinarios variaron en incidencia relativa $(5 \%$ de 10700 pesos en Areco y 17\% de 29000 pesos en Las Flores, ambos en 1857) y en los contenidos explicitados: donaciones y haciendas tomadas a los indios (20\% de 45000 pesos de ingreso presupuestado por la municipalidad de Azul) o rancho donado a beneficio de la escuela del pueblo (21\% de 71500 pesos en Chascomús) (MGEBA, legs. 13417, 13431, 13502 y 13547 , respectivamente).

La contribución directa, que con resultados cambiantes se había estado cobrando en las décadas anteriores quedó en manos del gobierno del Estado de Buenos Aires. Sin embargo, 10\% de lo recaudado correspondió a cada municipalidad, como antes sucedía con el juez de paz (Santilli, 2010). Desde el punto de vista de los ingresos municipales, los montos

públicos de los ejidos de los pueblos; 20 pesos por cada guía expedida; inspección anual a negocios por pesos y medidas utilizadas; $10 \%$ de la contribución directa cobrada en cada partido, y un único derecho de 100 pesos por cobrar por la delineación de edificios en cada solar. Las rentas municipales, uniformes desde la legislación, generaron combinaciones variadas en los presupuestos, que además fueron agrupadas de formas diferentes, lo que dificultó la sistematización de estas rentas.

${ }^{10}$ En algunos presupuestos, los municipales señalaban limitaciones para concretar los ingresos calculados. En la municipalidad de Bragado se expresaba en 1857 que las cosechas de maíz del partido no tenían extracción por el alto precio del transporte a la ciudad y que el número de vacunos en el partido era reducido porque la mayor parte se consumían por las fuerzas militares que guarnecían esa frontera (MGEBA, leg. 13563). 
calculados por la recaudación estuvieron por debajo del 13\% del total presupuestado en cada municipalidad.

Los derechos municipales sobre el uso y la propiedad de la tierra en los pueblos constituyeron una particularidad en Buenos Aires. El acceso a la tierra para conformar poblados no había presentado dificultades durante el siglo XVIII. Hacia la mitad del siglo XIX las municipalidades de campaña se convirtieron en reguladoras del ordenamiento de los edificios y la tierra pública en los pueblos con el asesoramiento del Departamento Topográfico. La morosidad en el tratamiento de un nuevo marco legislativo sobre la tierra pública, así como las controversias suscitadas por la pluralidad de derechos, influyó en el ordenamiento y el cobro de la renta. Por ejemplo, los municipales de Ensenada señalaban que, pese a la "dedicación esforzada", tenían "graves inconvenientes de donación de solares, suertes de quintas y chacras sin poseer límites fijos o al menos dudosos por la complicación que ofrece en este pueblo [Ensenada] la primitiva distribución de terrenos". Entre las limitaciones que la situación generaba se especificaba la carencia para el municipio de "este poderoso recurso de entrada” que le correspondía (MGEBA, leg. 13496).

Los montos por delineación de los edificios y ventas de solares, y en menor medida arrendamientos, estuvieron presentes en casi todos los presupuestos, aunque con incidencias variadas. En pueblos de frontera o con aumento de población, la incidencia en las estimaciones superó 30\% (Chascomús, Chivilcoy, Fortín de Areco, Patagones, Villa Mercedes, Zárate, y hasta 52\% para el nuevo pueblo de Las Flores) (Barcos, 2013; Canedo, 2011b; Valencia, 2005).

\section{LOS GASTOS PRESUPUESTADOS POR LAS MUNICIPALIDADES}

En los gastos presupuestados, las municipalidades reflejaron los recursos que consideraban necesarios para realizar algunas funciones entre las varias que tenían asignadas por ley. En pocos presupuestos, sus montos estuvieron vinculados a las entradas que habían calculado obtener.

Los rubros más frecuentes fueron los sueldos de los empleados de cada municipalidad, fundamentalmente el de secretario. Las autoridades no tenían sueldos asignados y la legislación otorgaba potestad a cada municipalidad para contar con un secretario "rentado por ella o sin sueldo, como ella lo estime mejor o posible" (artículo 32 del reglamento), por lo que sólo en tres presupuestos no se incluyó. Los ministros propusieron que la función se cumpliese entre los municipales por rotación, con una corta gratificación o por la incorporación de un suplente. Sin embargo, los sueldos de los secretarios fueron sostenidos por las municipalidades con cantidades 
que variaron entre 300 y 1000 pesos mensuales. Desde San Nicolás de los Arroyos llegó a proponerse que el presidente de la municipalidad también fuese rentado.

Para 1858 y 1859, en algunos presupuestos se incorporaron sueldos para quienes emprendían actividades específicas: el encargado de la construcción del cementerio, el comisario de Tablada, el encargado de trabajos públicos, el oficial empleado en la revisación de corrales de abasto, el encargado y peón del cementerio, el encargado de las medicinas, el empleado de policía, el recaudador de derechos de abasto y alumbrado público, el empleado del puerto, etc. Desde la municipalidad de San José de Flores argumentaban "dificultades para desempeñarse en sus respectivas atribuciones sin empleos subalternos, particularmente en la parte policial, por la extensión del partido y otras circunstancias" y presupuestaron cuatro sueldos de 300 pesos mensuales, además del secretario (1 000 pesos).

Los sueldos del preceptor, y a menudo de la preceptora, de las escuelas del Estado eran atribución del gobierno. Sin embargo, varias municipalidades buscaron complementarlos con un sobresueldo para sostener cubierto el cargo. Lo mismo sucedió con los útiles o premios para la escuela. ${ }^{11}$ En Baradero se incluyeron " 25 ps mensuales que se reciben del Departamento de Escuelas" para gastos, pero se presupuestaron "200 pesos de sobresueldo [...] por haberse comprometido la municipalidad a darle al preceptor" en 1856. En 1858, la municipalidad de San Pedro presupuestaba " 150 pesos para el alquiler de la casa de escuela de varones por ser limitado el monto dado por la Dirección de Escuelas". Los sobresueldos también fueron cuestionados por el ministro de Gobierno, pero fundamentaron y mantuvieron gastos por educación que complementaban los del gobierno. ${ }^{12}$

Un segundo grupo de gastos presupuestados estuvo orientado a los edificios públicos y su mobiliario. Ya fuese para el alquiler o compra de una casa para la propia municipalidad o la escuela, o bien para la construcción, traslado o reparación de la iglesia, el cementerio o la cárcel, los montos resultaron muy elevados en relación con las estimaciones de ingresos.

11 En el presupuesto general del Estado de Buenos Aires, se detallan los gastos correspondientes a los sueldos mensuales -uniformes- de un preceptor para la escuela de cada partido. Véase Registro oficial del gobierno de Buenos Aires (1857, planilla 22, pp. 210-211).

${ }^{12}$ La misma práctica de sobresueldo aparece en algunos casos para el cura del pueblo. Su sueldo formaba parte del ejercicio del patronato por parte del gobierno; a diferencia de los preceptores, los montos variaron por partido desde el gobierno: en Magdalena y San Antonio de Areco fueron de 100 y 150 pesos, en Quilmes y San Fernando, de 400 pesos, mientras que en zonas de frontera como Rojas y Junín (en conjunto), Patagones o Bahía Blanca era de 1000 pesos para cada uno. Registro Oficial del Gobierno de Buenos Aires (1857), Obispado, planilla 21. Sobre el sostenimiento económico de los curas en la campaña en un periodo anterior, véase Barral (2007). 
La municipalidad del pequeño pueblo de Arrecifes presupuestó 10900 pesos de ingresos y 364800 pesos de gastos en 1857. Estos se desglosaban en el sueldo de un secretario y gastos de escritorio (4 800 pesos) y la casa de juzgado, cárcel y cuerpo de guardia, el puente que divide el pueblo por arroyo, y otro puente para el río $(50000,10000$ y 300000 pesos, respectivamente). En San Fernando no incluyeron construcciones nuevas en 1858, pero la compostura de vías públicas, apertura de otras, arreglo de la plaza y del Cementerio presupuestados en 30000 pesos superaban, ellos solos, los 20600 pesos de ingresos.

En general, los cuestionamientos de los ministros hacia las construcciones presupuestadas por las municipalidades se orientaron a graduar los gastos: "emprender estas obras más adelante, cuando los recursos propios le den para llevarlas a cabo", escribió Vélez Sarsfield a la municipalidad de San Isidro, que proponía la construcción de la casa municipal y para escuelas; "no procurar proveerse de súbito de todo lo que necesiten" señaló Alsina a la municipalidad de Morón, agregando que en consecuencia debían suprimirse los gastos de cuartel y cárceles que había presupuestado. ${ }^{13}$ Los cambios anuales en los presupuestos correspondieron mayoritariamente a gastos moderados de mejoras de las casas que funcionaban como edificios públicos.

Un rubro que apareció en varios presupuestos fue el de las fiestas cívicas: "Con destino a la celebración de los aniversarios de 25 de mayo, 9 de julio y jura de la Constitución del Estado (3 000 pesos) [en Morón, o] semana santa y patrona del pueblo" (6 000 pesos) además de las festividades de mayo y julio (4 000 pesos) en Villa Mercedes. Asimismo, en la municipalidad de Monte justificaron el monto calculado para gastos eventuales y extraordinarios aduciendo que "las visitas a los pueblos de campaña de vuestra excelencia el señor gobernador, la del señor obispo y las fiestas cívicas absorben cuando menos esta cantidad" (10 000 pesos).

Además de los gastos reiterados, algunas particularidades también se pusieron de manifiesto en los presupuestos. La municipalidad del pueblo de Azul expresaba su situación de frontera y relativa lejanía de la ciudad de Buenos Aires al calcular como gastos mensuales la carne para la guardia (120 pesos), gratificaciones a chasques (250 pesos), subvención a 35 chas-

${ }^{13}$ Las obras públicas se incluyeron en 26 municipalidades (construcción del juzgado, la cárcel o rancho para presos, cuerpo de guardia, el cementerio, la escuela de varones y la de niñas, el templo, la casa parroquial y la construcción de corrales de abasto. Las refacciones de edificios públicos generalmente se refieren al techo, aunque también letrinas para el servicio del cura o la escuela de varones. En 1858 se incluyen, en algunos presupuestos, alumbrado, nomenclatura para calles, aperturas de nuevas vías o compostura de las existentes. 
ques al pueblo (50 pesos), y para obsequiar a Catriel y demás indios. ${ }^{14}$ Las municipalidades con puertos en su jurisdicción presentaron tanto ingresos específicos como gastos. La construcción de un camino que comunicara al pueblo de Zárate con la nueva ubicación del puerto fue presupuestada para que el gobierno "[facilite] algunos fondos con que poder llevar a cabo ese trabajo de tanta importancia para toda esta parte de la campaña", en referencia a su proximidad con la Confederación.

Los gastos presupuestados fueron constantemente observados por el ministro de Gobierno porque excedían en mucho los ingresos potenciales (véase cuadro 2).

Los montos presupuestados como ingresos se ubicaron mayoritariamente en el rango de hasta 30000 pesos (66\% de los presupuestos, 59 casos), otros 19 calcularon ingresos entre 31000 y 50000 pesos, y por encima de los 51000 pesos hubo once presupuestos. Los casos extremos corresponden a La Matanza, que incluyó gastos y municipalidades ubicadas en zonas de frontera o con población dispersa o reducida (Patagones, Bahía Blanca, Ensenada). Por otro lado, la populosa San Nicolás de los Arroyos presupuestó 108085 pesos en 1857 y 118100 en 1859 .

Por su parte, los montos de los gastos se distribuyen en los diferentes rangos, aunque se destacan los estimados en más de 81000 pesos (33\% de los presupuestos, 30 casos). Entre los más cuantiosos se encuentran los de Salto (más de 700000 pesos en 1859 y 520800 en 1857) y por encima de 400000 pesos, San Pedro, Arrecifes y San Nicolás. ¿Cómo explicar estas estimaciones de gastos? La incorporación de obra pública en los presupuestos resultaba determinante, aunque también había otros gastos calculados. Así, desde Salto en 1857 (no contamos el detalle de 1859) consideraron gastos por más de 500000 pesos: la construcción de casa para la escuela de niñas $(60000)$, de varones (60 000), reparaciones del templo (200 000), un cementerio (100 000), una casa de prisión (30 000); sueldos de secretario (2 400), de comisionado para los corrales y recaudación de rentas (3 600), de preceptor y preceptora, y gastos de escuelas y para los alquileres (26 400), y asignación al juzgado y partida de policía (38 400). O, en San Pedro (1857), además de los gastos ordinarios (43500 pesos) se consideraban los extraordinarios en 537000 pesos, que incluían fundamentalmente la canalización del arroyo (200 000), refacción del templo (300 000), el corral del abasto (10 000), un carro fúnebre (6 000) y el arreglo de la vía pública $(15000)$. Tras este panorama analizaremos a conti-

\footnotetext{
${ }^{14}$ En 1856 Juan Catriel, el joven, y el gobierno de Buenos Aires realizaron un tratado de paz por el cual el cacique y su gente retornaron a los territorios cercanos a Azul en el marco de una rectificación de la política ofensiva del gobierno y el restablecimiento del negocio pacífico de indios que implicaba la posibilidad de comerciar y recibir raciones (Jong y Ratto, 2008).
} 


\section{CUADRO 2. ESTIMACIONES PRESUPUESTARIAS DE INGRESOS Y GASTOS AGRUPADOS POR MONTOS (EN MILES DE PESOS MONEDA CORRIENTE)}

\begin{tabular}{lrr}
\hline Pesos & \multicolumn{1}{c}{ Ingresos } & Gastos \\
0 & $1(1 \%)$ & - \\
$1-30$ & $59(66 \%)$ & $21(24 \%)$ \\
$31-50$ & $19(22 \%)$ & $17(19 \%)$ \\
$51-80$ & $5(5 \%)$ & $21(24 \%)$ \\
$81-+$ & $5(6 \%)$ & $30(33 \%)$
\end{tabular}

Total: 89 presupuestos.

Fuente: Archivo del Ministerio de Gobierno del Estado de Buenos Aires, Archivo General de la Nación (véase cuadro 1).

nuación la dinámica de los déficits presupuestados por las municipalidades entre 1856-1859.

\section{LOS DÉFICITS EN LOS PRESUPUESTOS MUNICIPALES}

En el Estado de Buenos Aires, la mayoría de los presupuestos municipales se caracterizó por presentar déficits significativos, producto de estimaciones de ingresos con rentas limitadas y gastos ambiciosos. De los 89 presupuestos elevados por las municipalidades entre 1856 y 1859 que hemos ubicado, 82 casos (92\%) presentaron déficits, cuatro fueron presupuestos equilibrados y en tres casos se estimaron saldos favorables. ${ }^{15}$ La incidencia del déficit en cada uno de los 82 presupuestos tuvo importantes variaciones (véase cuadro 1).

Al observar en conjunto una problemática que se planteaba en forma simultánea, hemos considerado la incidencia de los déficits en relación con los gastos estimados en cada presupuesto. Es decir, establecimos el porcentaje de los gastos presupuestados que no llegaba a ser cubierto por los ingresos estimados (véase cuadro 3).

De los 82 presupuestos municipales considerados 47 (57\%) presentaron déficits que alcanzaban a más de $50 \%$ de los gastos (véase cuadro

${ }^{15}$ Aunque son 94 los presupuestos ubicados, no incluimos dos expedientes incompletos de 1856 porque no se especifican los totales, ni otros tres que son las primeras versiones de presupuestos que volvieron a presentarse. 


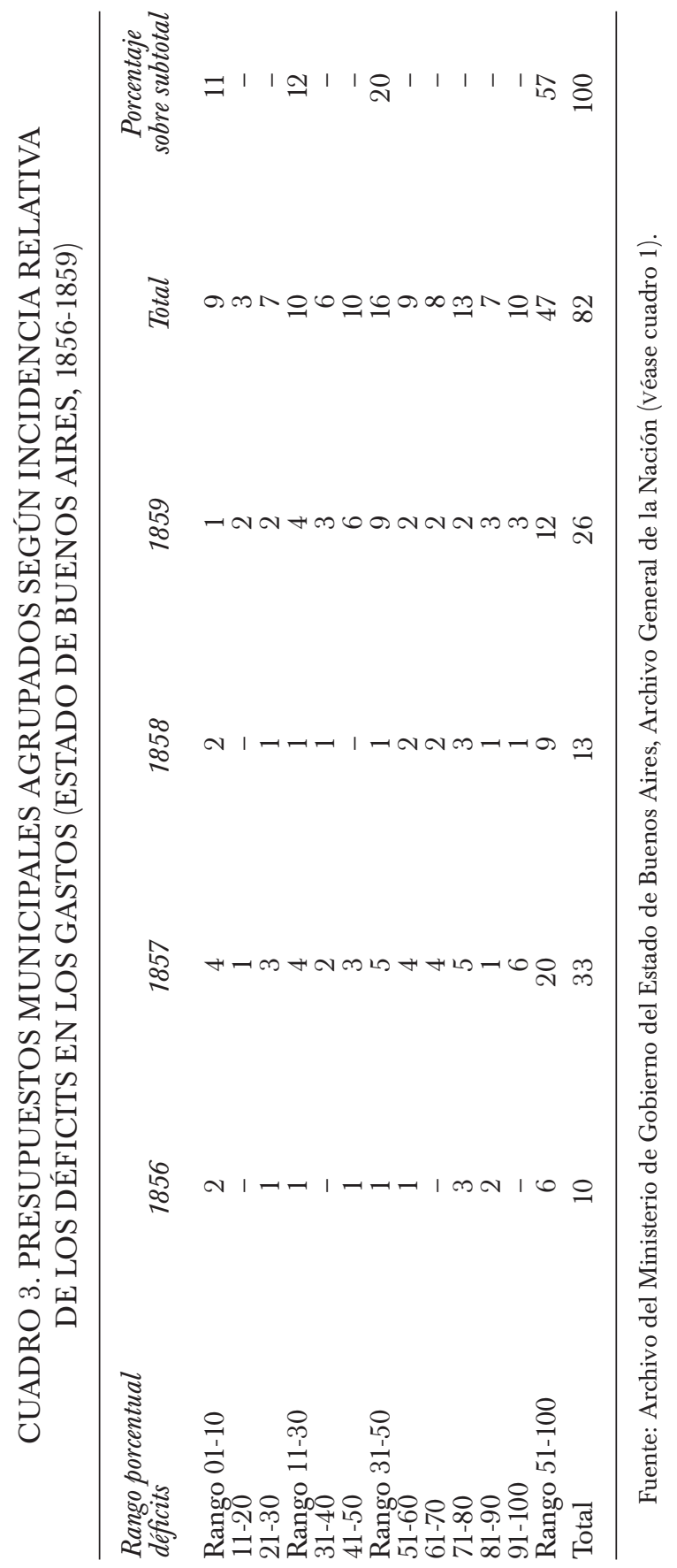


2). Si incluimos una incidencia de déficits de más de 30\% en los gastos, como otro rango posible, serían 67 los presupuestos en esa situación (77\%). Como contrapartida, hemos considerado los nueve presupuestos con déficits cuyo rango de incidencia varió entre uno y $10 \%$, ya que fueron los casos que el gobierno estuvo dispuesto a cubrir, pese a no lograr el equilibrio (déficit cero).

Si bien resulta frecuente encontrar presupuestos de cuerpos políticos o instituciones ejecutados con déficits durante el siglo XIX y, particularmente, en el ámbito municipal en las provincias de la Confederación, la situación en Buenos Aires amerita ser analizada. ¿Cuál fue el sentido que las reiteradas presentaciones de presupuestos con déficits altos tuvieron para el gobierno y las municipalidades de campaña en el Estado de Buenos Aires? Las argumentaciones sobre gastos presentados en los primeros presupuestos municipales permiten comenzar enfocando una cuestión articuladora en la política de los presupuestos: cómo se cubrirían los déficits en esa compleja coyuntura.

Por un lado, como hemos señalado, las municipalidades solicitaron al gobierno que les cubriera los gastos presupuestados que no podían sostener, pero el gobierno argumentaba que no podía hacerlo. Así, en el primer presupuesto de 1856, el juez de paz y presidente de la municipalidad de Morón justificaba que había calculado las erogaciones indispensables para poder funcionar debidamente, dejando otras para 1857. Sin embargo, incluía en el presupuesto: "compostura de calles, arreglo del pueblo y recomposición y conclusión del edificio público que sirve de escuela, pero el estado de ruina de ellos hace indispensable su refacción antes del invierno, además el edificio se halla en la plaza pública, consta de una sola pieza, aunque espaciosa no está cercada, y carece de las oficinas necesarias con grave perjuicio de la moral". Valentín Alsina, ministro de Gobierno en ese entonces, respondía que el gobernador encontraba el presupuesto "muy subido, no quizás porque lo sea en sí mismo, sino porque lo es con relación a la posibilidad de cubrirlo, mucho más cuando el gobierno tiene que atender a los que causen las demás municipalidades" (MGEBA, leg. 13 503).

En otros casos, diálogos similares incorporaron argumentos vinculados a la coyuntura, aunque sin hacer referencia a los enfrentamientos con la Confederación. Vélez Sarsfield fundamentaba la no cobertura del déficit de la municipalidad de San Pedro en los siguientes términos: "en atención al erario público agobiado con las inmensas erogaciones a que tiene que hacer frente para la defensa de la frontera y sostén del ejército que la guarnece como igualmente por la atención que tiene que prestar según le es posible [...] a exigencias análogas de los demás Partidos de Campaña” (MGEBA, leg. 12365). 
A su vez, la municipalidad de Azul solicitaba ayuda económica para cubrir su déficit, argumentando, con base en entradas estimadas en 45000 pesos y salidas superiores a 70000 pesos, que "a no ser por el generoso desprendimiento de algunos honorables vecinos y aun los sacrificios pecuniarios de los señores que componen la corporación, muy difícilmente se pudiese hacer frente a tantas salidas [...] que resultan al bien procomunal" (MGEBA, leg. 13 502).

Sin embargo, la comunicación entre el ministro y la municipalidad no siempre fue eficaz: "a consecuencia de no haberse obtenido contestación alguna del gobierno al presupuesto que elevó esta corporación el año próximo pasado de 1857, se halla este municipio [San Fernando] sin recurso alguno para atender a los ramos que le están recomendados" (MGEBA, leg. 13 825).

Una aclaración realizada tanto por Alsina como por Vélez Sarsfield fue el alcance del artículo 73 de la ley de municipalidades sobre la cobertura de los déficits por parte del tesoro general del Estado de Buenos Aires. $\mathrm{El}$ artículo 73 expresaba: "Mientras las rentas municipales no alcancen a cubrir los gastos que demande el servicio del partido, el tesoro general del Estado proveerá las cantidades que falten para cubrir el presupuesto de cada distrito." Sin embargo, los déficits serían considerados en la medida en que estuvieran incluidos en el presupuesto general aprobado por las cámaras. Igualmente, se mantuvieron algunos reclamos. La municipalidad de Rojas postergaba el arreglo del frente de la iglesia: "para cuando esta municipalidad tuviese fondos o, que su excelencia el señor gobernador se dignase hacerle el bien de darle alguna parte de la cantidad votada por las cámaras para atender en parte a las necesidades de las municipalidades de campaña; siendo esta de las manifestadas por su escasez de recursos" (MGEBA, leg. 13 571).

Efectivamente, en el presupuesto general del Estado de Buenos Aires para 1857 (planilla 32) se especificaron 2000000 de pesos para la municipalidad de ciudad y la de campaña repartidos en 1500000 para atender al déficit de la municipalidad de ciudad y 500000 para la campaña. ${ }^{16}$

Un segundo aspecto por considerar es que el ministro de Gobierno de turno cuestionó determinados rubros de los gastos presupuestados por cada municipalidad con el fin de reducir los déficits. Tras las observaciones del ministro, cada presupuesto fue devuelto a la municipalidad para su reformulación y posterior entrega al gobierno a fin de que pudiera determinar el modo de cubrir su importe. Sin embargo, los ajustes realizados no

${ }^{16}$ Sobre la cobertura de los déficits reales de la municipalidad de la ciudad de Buenos Aires por el gobierno del Estado y a partir de 1861 por las rentas de la nación, véase Garavaglia (2015, pp. 105-108). 
fueron siempre relevantes en su conjunto. En el caso de Morón, el ministro Alsina había indicado la supresión del sueldo de secretario por ese año, la disminución del gasto de las fiestas cívicas y la necesidad de detallar -además de reducir- los 40000 pesos para la compostura de calles y del edificio público que se utilizaba como escuela que figuraban como gastos indispensables en el primer año en el arreglo del pueblo. Sintetizamos los ajustes realizados en 1856 y cómo continuaron los déficits en el cuadro 4 .

La poca variación en los ingresos y gastos estimados es notoria en este caso, con excepción de la disminución de gastos en 1859. El caso amerita ser profundizado, pero revela el poco impacto de los ajustes solicitados en 1856.

Sin embargo, hubo algunas reformulaciones de presupuestos más marcadas. En la municipalidad de Baradero ante las primeras observaciones disminuyó la incidencia de su déficit a la mitad (de 80 a 40\%), y quedó un monto de 20000 pesos, que se mantuvo aproximadamente igual en 1857 y 1858 (con déficits de 38 y 39\% en relación con los respectivos gastos). Por el aumento de sus ingresos en 1859, disminuyó a 14450 pesos (25\% de déficit). En otras municipalidades, los presupuestos reelaborados llegaron a presentar una estimación de ingresos y gastos equilibrada, como San José de Flores, o con un déficit bajo, como Luján (5\%) (véase cuadro 1).

En tercer lugar, encontramos que la convocatoria por parte del gobierno y las cámaras para que las municipalidades elaborasen propuestas de nuevas rentas generó expectativas de aumento de ingresos. Los proyectos se presentaron, pero su aprobación por parte de la legislatura fue dilatada. Este desfase fue señalado por los propios presidentes de las municipalidades en varias oportunidades a partir de no realizar el envío de un nuevo presupuesto, como en el caso de Chivilcoy, que aclaraba que "como el proyecto de impuestos no ha sido por ese ministerio o por las cámaras provisto, entendiendo por ello que debería esperar alguna resolución sobre aquellas" (MGEBA, leg. 13 511). Además, las propuestas actuaron como parte de la justificación del déficit del presupuesto presentado. El presidente de la municipalidad de Baradero intentaba justificar el déficit objetado por el ministro de Gobierno, aduciendo que "al elevar el presupuesto para el año [18]57 lo hizo bajo la inteligencia de que aprobado el proyecto de nuevas rentas que acompañaba, produciría un resultado capaz de hacer frente y aun superar todos los gastos" (MGEBA, leg. 13 540). En 1857, el juez de Paz de San Andrés de Giles remitió el presupuesto de gastos y recursos para el año 1858, y señaló que, si las Honorables Cámaras aprobaban un impuesto para todos los frutos que se extraían del partido y las haciendas que se marcaban, el déficit de 32420 pesos bajaría entre 3000 y 5000 pesos.

Por último, mencionemos otros caminos seguidos para cubrir los déficits municipales, aunque fuese parcialmente. Pese a los diferentes cuestionamientos de los ministros, encontramos que el gobernador otorgó la 
Am. Lat. Hist. Econ., año 25, núm. 2, mayo-agosto, 2018, pp. 146-174

CUADRO 4. INGRESOS, GASTOS Y DÉFICITS PRESUPUESTADOS POR LA MUNICIPALIDAD DE MORÓN (1856-1859)

\begin{tabular}{lrrrr}
\hline Año & Ingreso & Gastos & Déficits & Porcentaje \\
1856a & & & & \\
$1856 \mathrm{~b}$ & 15200 & 65000 & -49800 & 77 \\
1857 & 15200 & 58000 & -42800 & 74 \\
1858 & 15200 & 65600 & -50400 & 77 \\
1859 & 15500 & 43500 & -28000 & - \\
\hline
\end{tabular}

Notas: no contamos con el presupuesto de 1858 . El porcentaje corresponde a la incidencia del déficit en el gasto presupuestado.

Fuente: Archivo del Ministerio de Gobierno del Estado de Buenos Aires, legs. 12682; 13503; 17264. Archivo General de la Nación.

suma de 5000 pesos a algunas municipalidades. Vélez Sarsfield dispuso para San Isidro que se le entregasen 5000 pesos (menos de 5\% del déficit) para cubrir el déficit enunciado; la misma suma figuró en el presupuesto de la municipalidad de Bragado en 1858 como donación del gobierno para ayudar en la construcción del cementerio.

Algunas municipalidades solicitaron préstamos a terceros, lo que generó una deuda correspondiente. San Isidro fue una de las cinco municipalidades que incorporó tal deuda en los presupuestos, y consideró su cobertura como una necesidad urgente: 27615 pesos en 1856 y 1857, para aumentar a 34676 en 1858. Las deudas estaban compuestas por 80000 pesos con la Casa de Moneda para atender a la iglesia del pueblo, la amortización de la deuda a razón de 5000 pesos por trimestre y la deuda a Victorino J. Escalada por haber facilitado maderas y dinero para la construcción en parte del cementerio (según el presupuesto de 1858, aunque en 1856 y 1857 figuraba por maderas invertidas en la casa rectoral del pueblo). ${ }^{17}$ Otro caso fue el de la municipalidad de Rojas, que señalaba la escasez de recursos para la construcción y terminación de obras a fin de justificar la deuda de 18000 pesos que se produjo por este rubro (pero que formaba parte del déficit mayor presupuestado de 72111 pesos).

En el presupuesto de gastos remitido el año pasado para este de 1858, había un déficit de 18000 pesos m/c; déficit, que esta municipalidad creyó que s. e. el sor. gobernador cuyo carácter filantrópico, le es conocido hubiera entonces favore-

${ }^{17}$ La deuda de la municipalidad de Belgrano de 40000 pesos fue detectada por el gobierno a partir de un resumen de gastos, pero su aclaración y pago llevaron varios años. 
ciéndola, remitiéndolo [...]. No habiéndole sido posible al señor gobernador entonces, favorecer a este municipio, esta municipalidad se dirigió al señor don Juan Cano pidiéndole prestada la suma de 15000 pesos para con ellos hacer concluir el interior del templo, para que el curato pudiese funcionar (MGEBA, leg. 13 571).

El aporte de los vecinos, práctica de larga data en estas sociedades cuyos alcances resulta difícil de justipreciar, fue una modalidad de cobertura de gastos específicos también presupuestada. Alsina había señalado a la municipalidad de Morón sobre las fiestas que: "esos gastos siempre se han costeado por suscripciones de los patrióticos vecindarios de los pueblos de la campaña, y por otros arbitrios que han inventado: cuyo recurso no deben abandonar hoy las municipalidades, y aunque eventual, él ha debido figurar en el cálculo de los ingresos" (MGEBA, leg. 13 503).

La municipalidad de Azul en 1858 los incluyó en el presupuesto al precisar que los "obsequios para Catriel y demás indios [eran] costeado[s] entre los vecinos y el municipio a 2000 pesos cada uno” (MGEBA, leg. 13 502).

Cada ministro fomentó la contribución del vecindario en diferentes rubros: en la compostura y apertura de calles en San José de Flores, en especial "los propietarios que mayor bien recibirán"; para los adornos y muebles de la municipalidad en Baradero, apelando al "patriotismo del vecindario que debe tener el mayor interés en su brillo y comodidad"; o para reparar el templo en San Isidro se aconsejaba "echar mano del arbitrio de subscripciones voluntarias de algunos vecinos, afectando al efecto al patriotismo y sentimientos religiosos de los habitantes del Partido".

Por su parte, las municipalidades vincularon las contribuciones de los vecinos con fundamentos para pedir otras ayudas al gobierno. La municipalidad del Fortín de Areco tenía reunida la cantidad de 43000 pesos proveniente de "fondos municipales y de algunas donaciones hechas por este vecindario [Fortín de Areco] hasta la fecha" y solicitaba la ayuda faltante al gobierno para una construcción. ${ }^{18}$

Por último, consideremos que los presupuestos con altos déficits no fueron aprobados, y que las formas de reducir los déficits al parecer fueron variadas: recibir ayuda del gobierno, ajustar los presupuestos, contraer deudas, solicitar colaboración de los vecinos o priorizar gastos. También encontramos estas acciones en aquellos presupuestos que se presentaron relativamente equilibrados y que el gobierno cubrió. ${ }^{19}$ Fueron nueve pre-

\footnotetext{
${ }^{18}$ Aún en 1861, la municipalidad de Ensenada no presupuestó la construcción del cementerio, "porque tiene fundada esperanza de poderlo llevar a cabo con las donaciones de los vecinos"; no obstante, sí presupuestó para el camino del Bañado que conectaba el Pueblito con el resto del distrito.

${ }^{19}$ En conjunto, las municipalidades fueron Exaltación de la Cruz, Villa de Luján, Las Conchas, y un presupuesto -sea porque no contamos con otro, o porque hubo variaciones entre los años- de Areco, Ensenada, Mercedes, Pergamino, Ranchos, 25 de Mayo, San José de Flores y
} 
supuestos con déficits con incidencias hasta 10\% de los gastos calculados y casos con déficits cuyos montos eran reducidos, más allá de la relación con las entradas y los gastos estimados. Así, en 1857 se aceptaron los presupuestos que presentaron tanto la municipalidad de Ensenada, con un déficit de 1550 pesos (29\% en relación con el gasto), como la de San Antonio de Areco, con 2200 pesos (17\%).

La variada combinación de entradas y gastos hace difícil establecer un tipo común de presupuesto para estos casos sin déficits altos, aunque podemos mencionar la moderación en los montos presupuestados como gastos $\mathrm{y}$, específicamente, que las construcciones quedaron desplazadas por arreglos. En algunos presupuestos contribuyó al equilibrio que se estimara una renta con monto importante, como en Mercedes, donde los ingresos por delineaciones y permisos para edificar se calcularon en 14000 pesos (32\% de los ingresos) en 1857, lo que concordaba con el aumento de donaciones de terrenos (Barcos, 2013, p. 152). En otros casos, hubo pedidos al gobierno que excedieron el presupuesto original, como en San Antonio de Areco, cuyo modesto presupuesto fue equilibrado, pero no incluía secretario, ni alquiler de casa para la municipalidad, ni gastos de escritorios. La municipalidad solicitaba el aval para levantar un plano y presupuesto para la iglesia que se encontraba muy deplorable e imploraban su ayuda para la obra. ${ }^{20}$ El presupuesto y el aval fueron aprobados y, además, Vélez Sarsfield reservó "un secretario para ser remitido oportunamente a las honorables cámaras". De incorporarse ambos en el presupuesto, el déficit hubiese sido mayor y más difícil de justificar su cubrimiento por parte del gobierno.

\section{CONCLusiones}

La incorporación a la política de los presupuestos de la fase de elaboración de dichos documentos en el ámbito municipal, anterior al tratamiento en las cámaras, permitió considerar una gama de prácticas diversas, decisiones e intereses de las propias municipalidades que de otra manera quedaban ocultas en las planillas de los presupuestos. A la vez, las formas

\footnotetext{
Patagones. Los tres presupuestos estimados con saldo favorable figuran en la planilla resumen presentada en 1859 por el ministro de Gobierno a las cámaras y corresponden a Lobos, Luján y Pilar (12, 52 y 54\% respectivamente, en relación con los cálculos de ingresos). Desconocemos su composición u objetivo del superávit, aunque quizá correspondió a fondos para un futuro gasto mayor. Los presupuestos equilibrados se realizaron dos en 1856 y dos en 1857 y correspondieron a Las Conchas, en ambos años, San José de Flores y Patagones.

${ }^{20}$ Sobre la historia del pueblo de Areco, referimos a Garavaglia (2009) donde se encuentra analizada la trayectoria y primacía en la vida política de los Martínez y allegados, con el nuevo gobierno.
} 
de instauración y las argumentaciones utilizadas pusieron de manifiesto características del proceso de constitución de las propias municipalidades, la conformación de jurisdicciones fiscales locales, así como la compleja situación del gobierno del Estado de Buenos Aires, que buscaba afianzarse como unidad política y económica soberana.

$\mathrm{El}$ régimen municipal fue parte del Estado de Buenos Aires desde su propia constitución con un criterio territorial amplio y sin requerimientos de cantidad de población; logró estar presente -de alguna manera- en más de $60 \%$ de los partidos de la campaña y en la ciudad. La presencia de los jueces de paz como presidentes de las municipalidades de campaña ha tendido a acentuar en los estudios las continuidades en el funcionamiento de los gobiernos locales, y ha opacado -argumentamos- las acciones de los municipales. Si bien las personalidades de ciertos jueces de paz, las situaciones de frontera o las dimensiones de los pueblos influyeron en las formas de ejercer el poder, algunas funciones de las municipalidades -como el ámbito fiscal o la distribución de terrenos en los pueblos- parecen haberse ejercido con una participación activa de los municipales encargados.

$\mathrm{Al}$ abordar el régimen municipal desde el ámbito fiscal, se puso de manifiesto la preponderancia que se le dio desde la legislación con la intención de regularla. Se trataba de la conformación de nuevas jurisdicciones fiscales y, eventualmente, de la naturaleza de las municipalidades. Sin embargo, la aprobación de los presupuestos municipales reveló dudas y divergencias en el propio gobierno y en las cámaras.

El anhelo del gobierno y las cámaras de lograr municipalidades uniformes en la campaña encontró limitaciones en el plano fiscal. La regulación que, sostenida por el ministro de Gobierno logró paulatinamente adecuar formatos, tiempos y ajustes de gastos para la presentación de los presupuestos municipales, constituyó, al mismo tiempo, una entrada a la política de los presupuestos que se tornó más compleja por el papel activo de las municipalidades.

Varias municipalidades ponderaron los artículos de la legislación considerando oportunidades. Estas apropiaciones, aparentemente no esperadas por el gobierno, generaron distintos comportamientos propios de la acción política. Así, la solicitud de cobertura de cada déficit municipal a través del tesoro general tuvo que ser aclarada por parte de los ministros; el nombramiento de un secretario con sueldo en cada una de las municipalidades logró ser sostenido por estas; las propuestas municipales de nuevas rentas quedaron a la espera de respuestas de la legislatura, pese a los reclamos locales.

El predominio de montos reducidos estimados como ingresos en la mayoría de las municipalidades reflejó tanto las limitaciones de las rentas 
como las características de los pueblos por esos años. Además de la transferencia de rentas como potestad municipal, algunos cambios se expresaron en relación con la importancia otorgada a los derechos por puerto en los pueblos frente a ríos y a los ingresos relacionados con solares y quintas. La implantación de estos derechos fue más morosa de lo anhelado por falta de infraestructura o falta de precisión en los derechos por la tierra.

A su vez, los gastos presupuestados parecen haber estado desvinculados de los ingresos posibles y centrarse en los recursos considerados indispensables para desarrollar las funciones asignadas a las municipalidades de campaña. Esta situación diseñó rubros compartidos en los gastos presupuestados, aunque combinados de diversas formas: sueldos o complementos de las aportaciones del Estado que variaban según la municipalidad, obras y reparaciones o alquileres para el funcionamiento del gobierno local, la escuela, la iglesia, el cementerio, la cárcel, junto con los gastos ocasionados por las fiestas fundamentalmente cívicas, aunque también algunas religiosas o las visitas del gobernador o el obispo.

Los déficits consecuentemente altos constituyeron la característica compartida por la mayoría de los presupuestos $-92 \%$ de los 89 analizadosdurante los cuatro años en que se realizaron en el Estado de Buenos Aires. Cómo se cubrirían los déficits presupuestados constituyó un asunto central para las posibilidades de gastos de las municipalidades, aunque la reconstrucción de las opciones seguidas para resolverla demuestra que también significó la construcción de vínculos políticos entre las municipalidades, el gobierno y eventualmente la legislatura.

El propio presupuesto, aun sin seguir un único modelo de presentación, parece haber formado parte de las estrategias utilizadas por las municipalidades para lograr ayuda económica o instalar una agenda de necesidades. En conjunto, más allá de constituir la primera vez que las noveles municipalidades de campaña elaboraban sus presupuestos y que estos eran tratados por el gobierno y la legislatura, los cambios en las prácticas fueron paulatinos y variaron según las municipalidades. Ante el seguimiento a los presupuestos presentados realizado por el ministro de Gobierno, caso por caso, las municipalidades emprendieron ajustes, mayores o menores, con base en los cuestionamientos recibidos. Suprimieron o graduaron algunos gastos, argumentaron a favor de otros y sostuvieron varios con montos medianos que quedaron instalados para esos años. Además, recibieron los sueldos y las ayudas previstas por el gobierno para la educación de varones y mujeres, pero los complementaron económicamente poniendo de manifiesto acuerdos previos contraídos con preceptores por sus remuneraciones, y las limitaciones de los montos enviados. En algunos casos contrajeron deudas con terceros $y$, de manera generalizada, mantuvieron la práctica de recurrir a los vecinos para solventar proyectos específicos de 
contenido variado (desde la reparación de la iglesia hasta los obsequios a indios amigos).

Unas pocas municipalidades presentaron presupuestos equilibrados o con déficits relativamente pequeños, aunque no necesariamente en todos los años. Moderación en los gastos y las construcciones convertidas en arreglos fueron características de esos casos, junto con la posibilidad de contar con un ingreso específico significativo o lograr concesiones por fuera del presupuesto, tal vez facilitado por afinidades políticas entre los municipales y el gobierno del Estado de Buenos Aires. Este último tema habrá de tratarse más a fondo en futuros estudios de casos.

En definitiva, la fiscalidad municipal no se construyó únicamente desde las cámaras legislativas y el gobierno. Las municipalidades se desenvolvieron, en esta fase de la política de presupuestos que hemos analizado, como actores difíciles de uniformar, que interactuaron con el gobierno y presentaron propuestas a las cámaras, además de que generaron diferentes acciones con vecinos de su jurisdicción y solicitaron préstamos por fuera de ella para estimar y cubrir los gastos. A mediados del siglo XIX, no constituían cuerpos con autogobierno pleno, pero mostraban márgenes de acción relativamente más amplios que lo que el gobierno y las cámaras parecían esperar, ya fuese por las concepciones sobre las municipalidades o las limitaciones del gobierno en esa coyuntura compleja.

\section{LISTA DE REFERENCIAS}

BARCos, F. (2013). Pueblos y ejidos de la campaña bonaerense. Una historia socio-jurídica de los derechos de propiedad y la conformación de un partido: Mercedes, 1780-1870. Rosario: Prohistoria.

Barral, M. (2007). De sotanas por la Pampa: religión y sociedad en el Buenos Aires rural tardocolonial. Buenos Aires: Prometeo.

BARral, M. y Fradkin, R. (2005). Los pueblos y la construcción de las estructuras de poder institucional en la campaña bonaerense (1785-1836). Boletín del Instituto de Historia Argentina y Americana Dr. Emilio Ravignani, 27, 7-48.

BARRIERA, D. (dir.) (2010). Instituciones, gobierno y territorio. Rosario, de la Capilla al Municipio (1725-1930). Rosario: Instituto de Investigaciones Socio-históricas Regionales de Rosario.

Birocco, C. (2009). Del Morón rural al Morón urbano. Vecindad, poder y surgimiento del Estado Municipal entre 1770 y 1895. Buenos Aires: Autor.

Bonaudo, M. (dir.) (2007). Liberalismo, Estado y orden burgués (1852-1880). Buenos Aires: Sudamericana. 
Bonaudo, M. y Sonzogni, E. (1997). Las finanzas municipales: una asignatura pendiente en la historiografía argentina del siglo XIX. El caso de Santa Fe (1953-1890). América Latina en la Historia Económica, 7, 27-34. DOI: 10.18232/alhe.v4i07.200

Canedo, M. (2011a). De presupuestos, auxilios y requerimientos económicos. La articulación entre los poderes locales y el gobierno del Estado de Buenos Aires a mediados del siglo XIX. En Primer Congreso Chileno de Historia Económica, Viña del Mar.

Canedo, M. (2011b). Mucho más que una cuestión de medidas. Las comisiones para el arreglo de los pueblos del Estado de Buenos Aires. Pergamino, Arrecifes, San Pedro, 1854-1856. En J. C. Garavaglia y P. Gautreau (eds.), Mensurar la tierra, controlar el territorio. América Latina, siglos XVIII y XIX. Rosario: Prohistoria.

Canedo, M. (2016). Los pueblos de españoles en la monarquía hispánica. La ampliación de jurisdicciones hacia el autogobierno (Buenos Aires, siglo XVIII y primeros años del XIX). Revista Prohistoria, 25, 3-27.

Canedo, M. y Román, C. (2016). Pueblos y municipalidades con puertos fluviales. Población y presupuestos en la conformación de los asentamientos locales (Buenos Aires, 1750-1860). Revista de Estudios Marítimos y Sociales, 9(9), 96-116.

Carmagnani, M. (2010). La economía pública del liberalismo. Orígenes y consolidación de la Hacienda y del crédito público, 1857-1911. En S. KunTz (coord.), Historia económica general de México. De la colonia a nuestros días. México: El Colegio de México/Secretaría de Economía.

Constitución del Estado de Buenos Aires (1854). Registro oficial del gobierno de Buenos Aires. Buenos Aires: Imprenta Americana.

Contr, V. y Boto, S. (1997). Finanzas municipales en el siglo XIX. La emisión monetaria como recurso fiscal en Argentina. América Latina en la Historia Económica, 7, 35-45. DOI: 10.18232/alhe.v4i07.201

Decretos (1857). Registro oficial del gobierno de Buenos Aires. Buenos Aires: Imprenta Americana, planilla 22, 210-211.

Fradkin, R. y Gelman, J. (2015). Juan Manuel de Rosas. La construcción de un liderazgo político. Buenos Aires: Edhasa.

Galarza, A. (2012). Prácticas comerciales y fiscalidad sobre la circulación de mercancías en la campaña porteña. Un estudio de caso: Chascomús entre 1780 y 1850 (Tesis doctoral). Universidad Nacional de Mar del Plata, Argentina.

Garavaglia, J. C. (2007). Construir el estado, inventar la nación. El Río de la Plata, siglos XVIII-XIX. Buenos Aires: Prometeo.

Garavaglia, J. C. (2009). San Antonio de Areco, 1680-1880. Un pueblo de la campaña, del antiguo régimen a la modernidad argentina. Rosario: Prohistoria.

Garavaglia, J. C. (2015). La disputa por la construcción nacional argentina. Buenos Aires, la Confederación y las provincias (1850-1865). Buenos Aires: Prometeo.

Garavaglia, J. C. y Caselli, E. (2013). Guerra, política y negocios en Buenos Aires. Las oficinas de Hacienda y los proveedores del Estado (1858-1860). Boletín del Instituto de Historia Argentina y Americana Dr. Emilio Ravignani, 39, 39-72. 
Gelman, J. (2000). Crisis y reconstrucción del orden en la campaña de Buenos Aires. Estado y sociedad en la primera mitad del siglo XIX. Boletín del Instituto de Historia Argentina y Americana Dr. Emilio Ravignani, 21, 7-31.

Halperín, T. (1995). Proyecto y construcción de una nación (1846-1880). Buenos Aires: Ariel.

Jong, I. y RATTO, S. (2008) Redes políticas en el área Arauco-pampeana: la Confederación indígena de Calfucurá (1830-1870). Intersecciones en Antropología, 9, 241-260.

Ley de Municipalidades (1854). Registro oficial del gobierno de Buenos Aires, pp. 107-118.

Míguez, E. y Yangilevich, M. (2010). Justicia criminal y Estado en la frontera de Buenos Aires, 1852-1880. En Boletín del Instituto de Historia Argentina y Americana Dr. Emilio Ravignani, 32, 107-137.

Paredes, R. (1995). Origen y poder. Poder económico y administración política en Buenos Aires, 1850-1910. Buenos Aires: Centro Editor de América Latina.

Paula, A. y Gutiérrez, R. (1999). Las ciudades y el medio rural. En Academia Nacional de la Historia (eds.), Nueva historia de la nación Argentina. Buenos Aires: Planeta.

ReCAlde, A. (2009). Las municipalidades de la provincia de Buenos Aires a través de la historia ¿̇autonomía o autarquía? La Plata: Instituto Cultural de la Provincia de Buenos Aires.

Ríos, E. (2013). Hacia un nuevo orden fiscal. Las formas de recaudación impositiva: instituciones, agentes y recursos. Santa Fe, Argentina (1852-1873) (Tesis doctoral). Universitat Pompeu Fabra, España.

SANJURJO, I. (2004). La organización político-administrativa de la campaña mendocina en el transito del antiguo régimen al orden liberal. Buenos Aires: Instituto de Investigaciones de Historia del Derecho.

SANTILl, D. (2010). El papel de la tributación en la formación del Estado. La contribución directa en el siglo XIX en Buenos Aires. América Latina en la Historia Económica, 33, 31-63. DOI: 10.18232/alhe.v17i1.428

Scobie, J. (1964). La lucha por la consolidación de la nacionalidad. Argentina, 1852-1862. Buenos Aires: Hachette.

Ternavasio, M. (1991). Municipio y política, un vínculo histórico conflictivo (Tesis de maestría). Facultad Latinoamericana de Ciencias Sociales, Argentina.

Valencia, M. (2005). Tierras públicas, tierras privadas. Buenos Aires, 1852-1876. La Plata: Universidad Nacional de La Plata.

\section{Archivos}

AGEBA Archivo del Gobierno del Estado de Buenos Aires. 